\title{
Aspects of Clinical Malpractice in Endodontics
}

\author{
Mothanna Alrahabi ${ }^{1} \quad$ Muhammad Sohail Zafar ${ }^{1,2}$ \\ ${ }^{1}$ Department of Restorative Dentistry, College of Dentistry, \\ Taibah University, Madinah Munnawara, Saudi Arabia \\ ${ }^{2}$ Department of Dental Materials, Islamic International Dental \\ College, Riphah International University, Islamabad, Pakistan \\ ${ }^{3}$ Department of Restorative Dentistry, College of Dentistry, \\ King Faisal University, Al Ahsa, Saudi Arabia
}

Necdet Adanir ${ }^{3}$

\begin{abstract}
Address for correspondence Muhammad Sohail Zafar, PhD, MSc, BDS, Department of Restorative Dentistry, College of Dentistry, Taibah University, Madinah Munawarah, 41311, Saudi Arabia (e-mail: mzafar@taibahu.edu.sa).
\end{abstract}

Eur J Dent 2019;13:450-458

\begin{abstract}
The clinical dentistry and endodontic procedures involve very technique-sensitive procedures, therefore exposing the operator to risks of causes not only damage to patients but also leads to malpractice. Among various disciplines of dentistry, endodonticsrelated cases witness the most frequently filed malpractice claims. This is due to the fact that the endodontic treatment procedures involve operative and surgical procedures, using a variety of medicaments and techniques. The endodontic procedural errors can be preoperative errors (such as incorrect diagnosis and misinterpretation), intraoperative errors including root canal and pulp chamber perforations, ledge formation leading to apical transportation or zipping, hypochlorite accidents, and fracture of instruments. More critically, failure to use rubber dam may result in inhalation or ingestion of endodontic instruments. Under such circumstances, the endodontist may have to face legal consequences. Due to the increased healthcare load and patients' awareness, it is important to know the legal ramifications of adverse effects, failed restorations, or other complications, to avoid any legal ramifications of endodontic procedures and associated techniques. Therefore, precautions must be taken to prevent any postsurgical complications, patient complaints, and/or failures. For this purpose, the operator must consider ethical principles and adhere strictly to the standards of

Keywords

- complications

- dentistry

- ethics

- medicolegal aspects

- root canal treatment healthcare while performing the diagnosis and treatment. A referral toward a specialist or consultant endodontist is always an appreciable option and should be considered in the best interest of the patient. The aim of the article is to highlight various aspects of malpractice in clinical endodontics, and associated materials and challenges. In addition, commonly occurring operating errors during endodontic treatment, possible consequences, precautions, and management have been discussed.
\end{abstract}

\section{Introduction}

Medical malpractice is an act of a medical professional deviating from the set regulations and standards that result in injury or damage to a patient. Another associated term is "medical negligence," that is, a careless action of a medical professional jeopardizing the required standards of healthcare. ${ }^{1}$ Dental malpractice is very similar to medical malpractice, where a dental professional fails to follow the required standards of practicing dentistry, thereby harming the patient. ${ }^{2}$ Although the matter of medical practice errors among healthcare professionals is well known and on the rise, the exact "numbers" have been always been difficult to collect, making it almost impossible to have a well-defined image of the phenomenon. ${ }^{2}$

The better understanding of patient's rights and organized protocols for compensating any damages has involved more public attention. As a result, the number of reported malpractice cases has increased remarkably in recent years among many parts of the world. ${ }^{3,4}$ Like any other healthcare professional, dentists are also exposed to risks of causing damage to patients, leading to malpractice. In such kind of circumstances, if a dentist risks the patients' life, or tissues or incurs any other damages, the dentist may have to face
DOI https://doi.org/

10.1055/s-0039-1700767

ISSN 1305-7456.
(C2019 Dental Investigation Society
License terms

(요 (1) $\odot \circledast$ 
legal consequences. ${ }^{5,6}$ There is no doubt that procedures performed by general dentists and endodontists are highly technique sensitive, and require a high-level of training, knowledge, as well as cognitive and psychomotor skills.? Among various disciplines of dentistry, endodontics-related cases witness the most frequently filed malpractice claims. ${ }^{8}$ For instance, endodontic malpractice claims have commonly been reported in $14 \%$ and $17 \%$ of Swedish ${ }^{9}$ and USA $^{10}$ populations, respectively. In Italy, a recent study reported a reasonable number of technical "errors" during endodontic procedures, including perforations (13\%) and broken instruments (6\%). ${ }^{11}$ In terms of reported malpractice claims, the majority of endodontic malpractice claims have been filed by women corresponding to their higher frequency of attending dental clinics compared with men. ${ }^{12}$

A remarkable proportion (>33\%) of filed claims were based on unconfirmed incidents, hence reflecting the high-level of awareness and ease of patients with regard to making such claims. ${ }^{13}$ Therefore, to guarantee the endodontist's own safety, record keeping and appropriate documentation (such as informed consent and clinical data) of all cases of suspected injuries is of vital value. ${ }^{14}$ The failure to follow the standards and treatment protocols strictly may not only compromise the quality of treatments and final outcome but also result in malpractice claims. ${ }^{15}$ On the other hand, commonly associated complications such as infection or persistent pain in the absence of any obvious pathology are not considered as cases of malpractice. ${ }^{16}$ With respect to malpractice versus procedural accident debate, medical malpractice is defined as the negligence arising out of the doctor-patient relationship, whereas negligence is the unreasonable act or omission by a provider that results in patient harm. ${ }^{17}$ Therefore, it is very obvious that due to the high-level of technique sensitivity, endodontics is the most involved specialty (28\%) in malpractice cases $^{18}$ compared with any other dental specialty, consequently requiring further attention. The aim of this article is to highlight various aspects of malpractice in clinical endodontics, and associated materials and challenges. In addition, commonly occurring operating errors during endodontic treatment and possible consequences have been discussed.

\section{Standard of Practice in Endodontics}

In the context of endodontic malpractice, it is vital to understand the significance and standards of endodontic practice. The standards of endodontic practice can be defined as the appropriate degree of prospects for professional interventions expressed by a professional or regulatory organization, which are based on evidence and designed using the currently available scientific knowledge and expertise. ${ }^{19}$ There is no concern or issue of doctor-patient choice if there is availability of better technology that offers predominantly superior results. For example, the apical surgery and retrograde root filling using ultrasonic tips and microscopy ${ }^{20,21}$ surely improved the standards of endodontic procedures.

Similarly, biocompatible and bioactive biomaterials such as mineral trioxide aggregate (MTA) and bioglass may perform better than amalgam for apical retrograde fillings. ${ }^{22}$ Although the term "standards of care" is reasonably established in law, it is rarely defined in medical terms. According to the tort law, it is defined as "the caution and prudence that a reasonable person under a duty of care, in similar circumstances, would exercise in providing care to a patient."23 There is a firm consensus among professional endodontists and legal personnel on recognizing the level of endodontic care. It refers to any clinical procedure that is carried out in the best interest of the patient and performed by a competent and trained endodontist.

\section{Endodontic Errors Categorization}

There exists a range of endodontic errors and endodontic malpractices committed by dental professionals during everyday clinical procedures. The typical injuries in endodontic malpractice are perforation and broken instrument. ${ }^{11}$ Operator-related factors had no impact on endodontic malpractice claims. ${ }^{24}$ According to the Danish Dental Complaint Boards (DCBs), practitioner's malpractice was considered if the patient was not informed about the potential consequences, persistent periapical pathology, or defective root canal fillings in a simple canal anatomy. However, severe bone and soft tissues injury while using paraformaldehyde-based solutions have been categorized as cases of malpractice in all types of root canals. ${ }^{16}$ In addition, the DCB defined other reasons for endodontic malpractice including defective or poor quality of apical seal, short of length root fillings, and over filled, over instrumented and unfilled root canals. ${ }^{16}$

For the ease of understanding, endodontic errors can be classified into preoperative, intraoperative, or post-operative errors. The majority of procedural errors occur during the intraoperative phase, including preparation of access cavity, missing canals, fracture of instruments, ledge, irrigant extrusion through apical foramen, under filling, and overfilling of the root canal obturation. According to Bjørndal and Reit, ${ }^{16}$ the endodontic malpractice claims were subcategorized as follows:

i. Technical complications as a result of improper treatment; for example, instrument fracture, perforation, and defective root fillings. A problem experienced by the patient because of treatment procedure directly; for example, infection, postoperative pain or tooth fracture case may be classified as "incorrect treatment."

ii. Persistent pain: the patient felt pain for an unacceptably longer period following treatment.

iii. Wrong treatment: the patient complained that the operator has treated either a wrong tooth or treated a tooth due to an incorrect reason.

iv. Prolonged treatment: prolonged management of patient, including extra appointments and associated complications.

v. Lack of information: insufficient information was provided to the patient regarding vital diagnostic or treatment procedures.

vi. Others: such as claims that are not associated with endodontic procedures, including an "unnecessary" 
endodontic procedure based on false diagnostic or a nonendodontic problem. ${ }^{16}$

Alternatively, endodontic errors can be classified on the basis of operative stages (-Fig. 1) such as preoperative (before starting the active treatment), intraoperative (during endodontic procedures), and postoperative (after the completion of endodontic treatment) errors.

\section{Preoperative Errors}

Preoperative errors such as incorrect diagnosis usually leads to misinterpretation or lack of information, either based on clinical or radiographic interpretation. ${ }^{25}$ Failure to locate the cause of pain results in misdiagnosis and wrong tooth being treated. To avoid such kind of mistakes in diagnosis, each and every suspected tooth should be investigated and tested for pulp vitality and appropriate diagnosis.

\section{Intraoperative Errors}

\section{Working without Rubber Dam}

Rubber dam remains mandatory and highly recommended for contemporary nonsurgical endodontic procedures. ${ }^{26}$ The use of rubber dam during endodontic procedures ( - Fig. 2) confers at least three main advantages ${ }^{27}$ :

i. Isolation and control of crossinfection,

ii. Protection from accidentally dropping instruments into pharynx or esophagus

iii. Improving treatment efficiency

Failure to use a rubber dam indicates that the clinician does not understand the microbial nature of the disease process and the importance of applying the rubber dam. The rubber dam provides protection to the patient ${ }^{28}$ and creates an aseptic environment. It enhances the vision, retracts tissues, and makes treatment more efficient. Soft tissues are protected from laceration by rotary instruments, chemical agents, and medicaments. Irrigating solutions are confined to the operating field. Most importantly, endodontic treatment under rubber dam is vital for patients' safety and protecting them from aspiration and swallowing of dental materials and endodontic. ${ }^{29}$ An additional advantage is that the dentist and auxiliary employees are also protected. ${ }^{30}$ The risk from aerosols is minimized ${ }^{31,32}$ and the dam provides a barrier against the patient's saliva and oral bacteria. ${ }^{33}$ Application of the rubber dam may also reduce the potential for transmission of systemic diseases such as acquired immunodeficiency syndrome (AIDS), hepatitis, and tuberculosis..$^{30,31}$

The use of the rubber dam in the United States is considered the standard of care; thus, expert testimony is not required in cases involving patients who swallowed or aspirated instruments or materials due to lack of rubber dam isolation. The juries are considered competent to determine negligence. Evidence exists that many general dentists unnecessarily place themselves at risk for not using the rubber dam while performing endodontic procedures. ${ }^{34}$ The consequences may include failure to protect the patient from aspiration or swallowing instruments, the spread of infection to dental

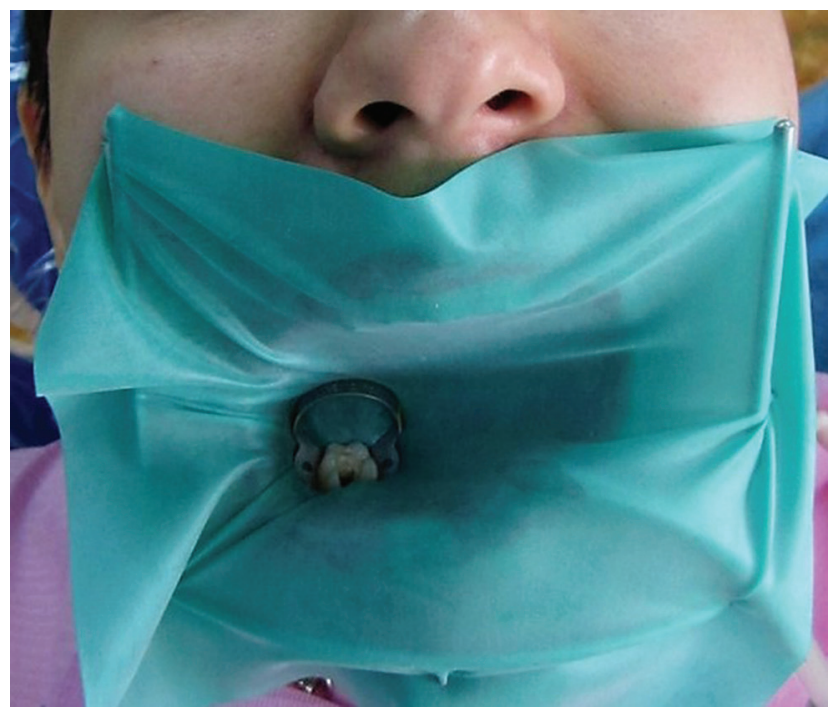

Fig. 2 A typical clinical image of rubber dam isolation during endodontic treatment; the tooth under treatment has been isolated from the oral cavity, hence preventing saliva contamination and spread of infection, and accidental aspiration or ingestion of endodontic instrument or any biomaterials.

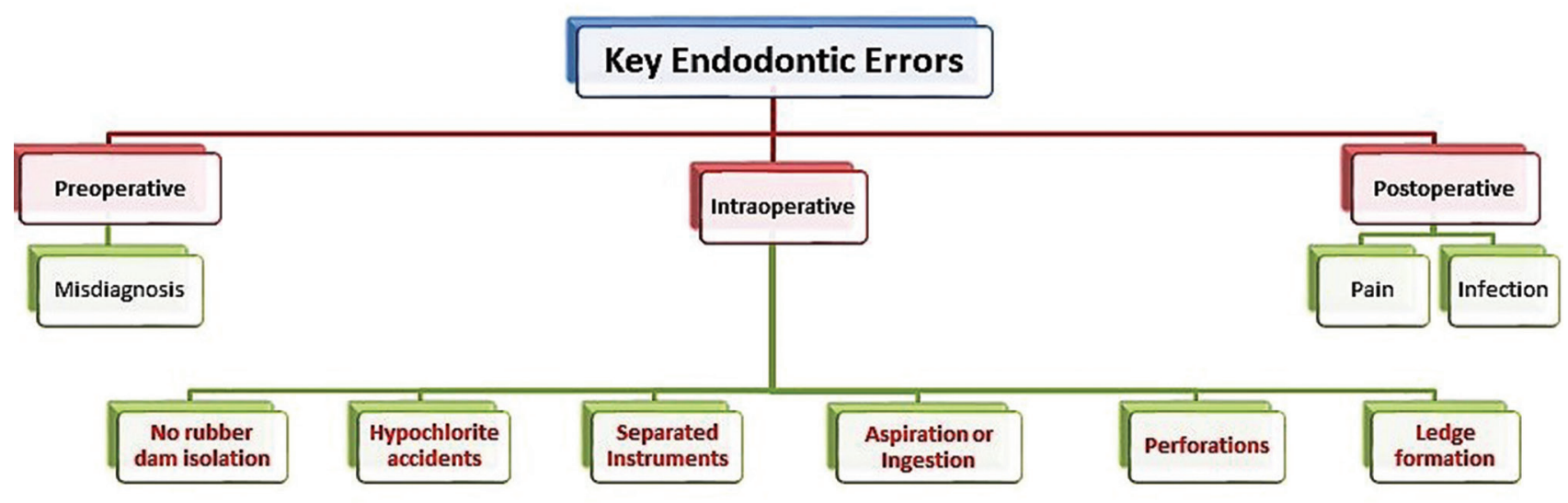

Fig. 1 Classification of various endodontic errors based on the operative stage. 
staff from contaminated aerosols, and the decreased success rate for treatment due to lack of asepsis. ${ }^{34}$

\section{Root Canal and Pulp Chamber Perforations}

Perforation is a type of communication of root canal to the external root surface (-Fig. 3A, B). The usual cause is iatrogenic due to improper use of endodontic instruments while accessing the preparation of cavity and exploring the root canals. ${ }^{35-37}$ Perforations complicate the root canal treatment further, for instance, searching for calcified/curved canals may result in strip perforation. ${ }^{38}$ Misplaced, endodontic, post for permanent restoration is another potential iatrogenic cause of root perforation. ${ }^{35}$ There are several noniatrogenic causes such as caries and root resorption. ${ }^{36,39}$ Such kinds of serious implications are reported in 2 to $12 \%$ of root-treated teeth. ${ }^{36,40}$ Upon establishment of an infected perforation, the affected tooth is likely to have a poor prognosis and may be lost due to associated complications.

A careful examination (clinical and radiographic) is very crucial to assess the morphology, and dimensions of the pulp chamber and root canals. Indeed, a strong theoretical knowledge about the internal anatomy and morphological features of the root canals is essential. ${ }^{41-43}$ Additionally, it is important to assess the relative root inclination/curvature, axis, possibility of pulp stones, and restoration types. Supplementary radiographs to rule out above-mentioned conditions can be indicated if needed. ${ }^{44}$

\section{Ledge Formation}

Considering the complexity of root canal treatment, the most frequently reported complication during endodontic instrumentation is the diversion of canals from its curvature ( - Fig. 4A, B). This can be further complicated by lack of communication with the periodontal ligament (PDL), leading to a practical error called ledge formation or ledging. ${ }^{45}$ It results when instrumentation is performed at a shorter length than the required working length, leading to canal blockade at the "short point," hence ledge formation. ${ }^{46}$

The ledge formation may exclude the possibility of attaining sufficient canal preparation (an incomplete instrumentation) and disinfection of the root canals, leading to short obturation. The lack of cleaning and shaping apical in the ledge results in residual infection, leading to recurrent periapical pathology. Considering these facts, ledge formation has been related to unfavorable endodontic treatment outcomes. ${ }^{47,48}$ In addition to ledge formation, cleaning and shaping of curved root canals may result in other errors such as apical transportation ${ }^{49-51}$ and zipping. ${ }^{52}$

\section{Hypochlorite Accidents}

In 1920 , Crane et $\mathrm{al}^{53}$ described using sodium hypochlorite $(\mathrm{NaOCl})$ for root canal debridement and disinfection. After getting the concept, several chemicals have been explored for root canal irrigation. ${ }^{54-58}$ Several studies ${ }^{59-65}$ have reported various harmful effects on soft oral tissues following inadvertent contact with $\mathrm{NaOCl}$ or calcium hydroxide $\mathrm{Ca}(\mathrm{OH})_{2}$. To avoid any unwanted consequences, an extreme care is required while using intracanal medicaments such as $\mathrm{NaOCl}$ and $\mathrm{Ca}(\mathrm{OH})_{2}{ }^{13}$

Factors associated with incidence of $\mathrm{NaOCl}$ or $\mathrm{Ca}(\mathrm{OH})_{2}$ injuries included type of teeth; for example, molars are less likely to be affected compared with premolars to sustain the $\mathrm{NaOCl} / \mathrm{Ca}(\mathrm{OH})_{2}$-associated injuries. Similarly, the risk of $\mathrm{NaOCl} / \mathrm{Ca}(\mathrm{OH})_{2}$ injuries is two-fold higher among patients treated in public sector clinics compared with patients treated in the private sector. The verified $\mathrm{NaOCl} / \mathrm{Ca}(\mathrm{OH})_{2}$ injuries revealed no usual association with the age of patient or practitioner. ${ }^{13}$ Although $\mathrm{NaOCl}$ is a potent intracanal irrigant, ${ }^{53}$ it has to be handled with appropriate safety measures. It is considered very safe if used with all precautions,
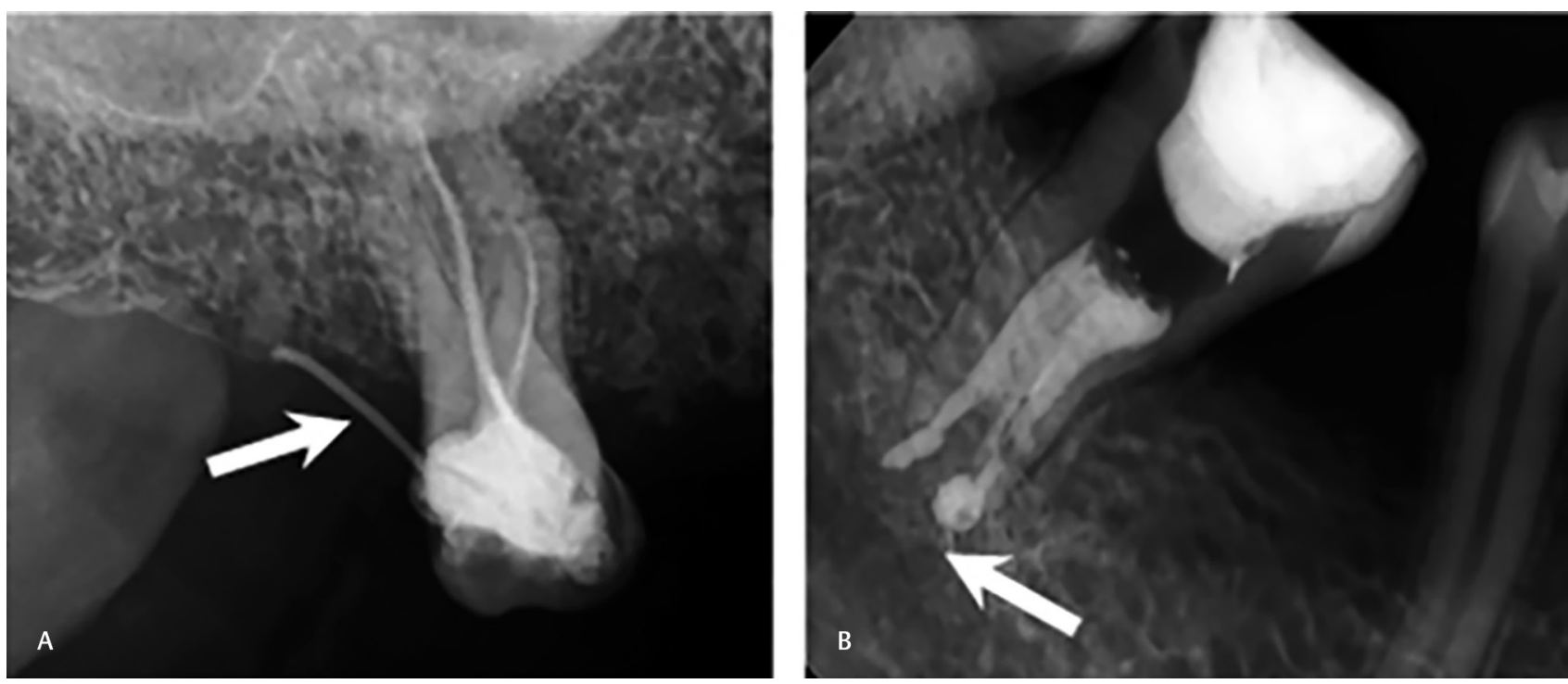

Fig. 3 Periapical radiographs showing perforation of root canals communicating with the internal root canals to the external root surface, hence leading to blood contamination of the pulp space and potential infections; (A) bur perforation (arrow) of lateral wall of pulp chamber, leading to obturation materials and misdirecting into the gingival tissues, and (B) apical perforation (arrow) due to mechanical over instrumentation leading to extrusion of the obturation through the apical foramen. 
proper suction, and rubber dam application. However, occasionally, complications may result from accidental spillage in the following manner:

i. Damage to clothing, eyes, skin, and oral mucosa $a^{59}$

ii. Expression of $\mathrm{NaOCl}$ outside root canals and consequent (hypochlorite accident) ${ }^{66}$

iii. Accidental misuse or extrusion to maxillary sinus. ${ }^{67,68}$

iv. Wedging of a needle in the canal or into a perforation ${ }^{69,70}$

v. Robust expression of $\mathrm{NaOCl}$, causing its penetration into periradicular tissues, which may lead to inflammation, discomfort, serious injury to periapical tissues, and life-threatening emergency. ${ }^{67}$

Loose insertion of needle, careful irrigation using a light pressure, and perforated needle ${ }^{67}$ prevents irrigating solution from being forced into alveolar bone. Sudden and sharp pain during irrigation followed by a diffuse swelling suggests likely penetration of solution into the periradicular tissues. The acute episode subsides spontaneously with time. In teeth with open apices, the use of less concentrated irrigant, or saline, prevents the possibility of irrigant accidents. Surgical drainage and antibiotics are not indicated in the initial stage. Usual management is supportive; analgesics (non-steroidal anti-inflammatory drugs) should be prescribed and patients reassured. As the outcome is very unpredictable, evaluation must be performed frequently to follow-up the progress of healing.

\section{Separated Instruments}

An unfortunate occurrence is the fracture of endodontic instruments (such as file, reamer) inside the root canal (-Fig. 5A-C) which may obstruct the access to the root
A

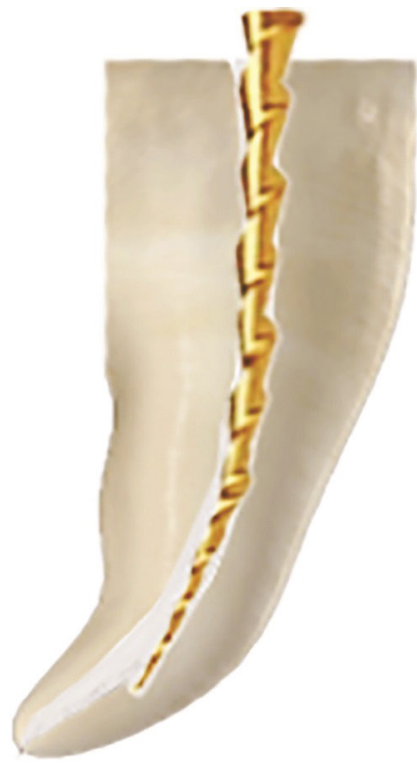

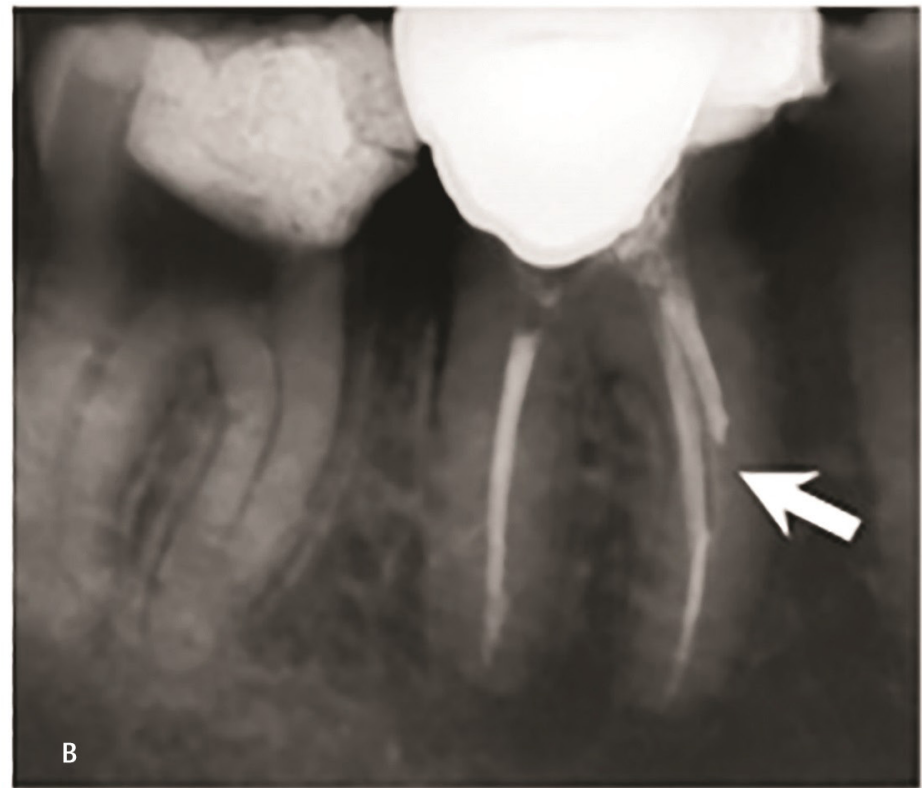

B

Fig. 4 Inappropriate mechanical instrumentation during cleaning and shaping of root canals; (A) schematic presentation of ledge formation typically using a large-sized or rigid file in a curved root canal (B) a periapical radiograph showing incomplete cleaning and shaping of a root canal due to ledge formation (arrow) or obstruction.
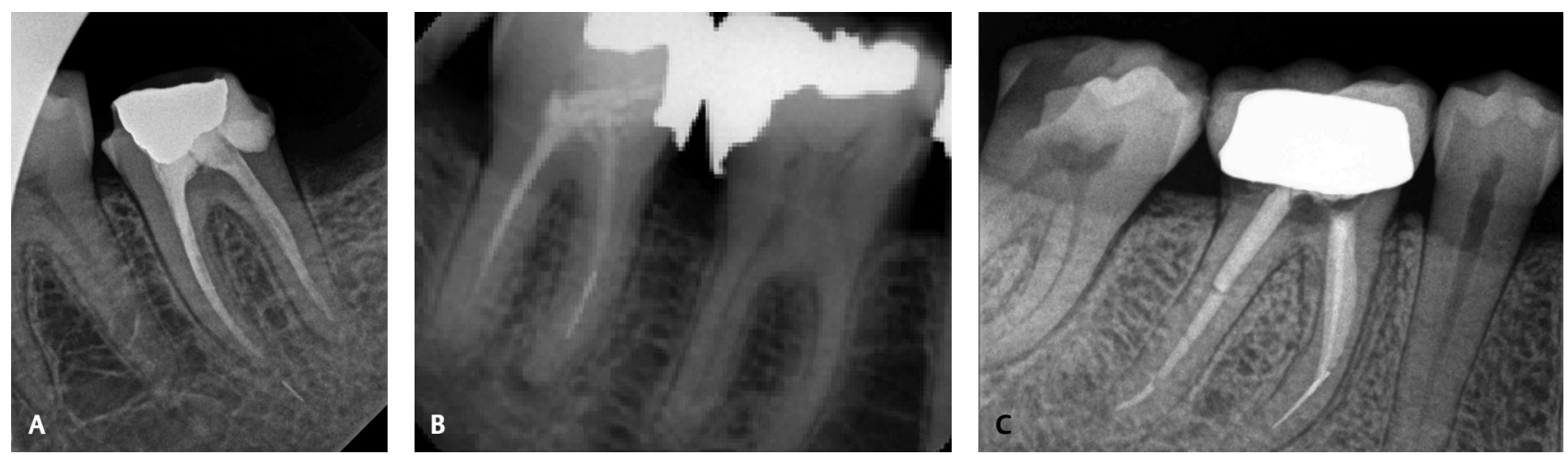

Fig. 5 Periapical radiographs showing the endodontic instruments fractured during root canal treatment: (A) a broken endodontic file (arrow) extruded through the apical foramen which may cause irritation or foreign body reaction in the periapical area (B) a broken endodontic file (arrow) obstructing access to the apex and making cleaning and shaping of apical part of root canal challenging (C) a endodontic file (arrow) in the apical third of the root canal, hence compromising the further cleaning and shaping of apical seal of the affected root canal. 
apex, endodontic treatment, and prognosis. ${ }^{71}$ The fracture of instrument incidences mainly depend on multiple factors such as type of instrument (files, reamers), material (stainless steel [SS], nickel-titanium [NiTi]), fatigue strength, and clinical handling. For instance, the fracture rates of SS instruments have been reported significantly lower $(0.25 \%$ and 6\%), compared with the fracture rate of NiTi instruments $(1.3 \%$ and $10.0 \%){ }^{72,73}$ corresponding to better elasticity and cyclic fatigue strength of SS alloy. The fracture of endodontic instrument is almost impossible to avoid and may occur by an experienced operator working with all precautionary measures, thereby frustrating both practitioners and patients. Common reasons for instrument separation are torsional or flexural fatigue and crystallographic defects. ${ }^{74,75}$ These instruments do not show any sign of cyclic fatigue, discoloration, and cracks of bends. To prevent such complications, endodontic instruments should be used with care and must be discarded after using two to three times. In addition, proper training of using endodontic instruments is vital in preventing these complications. ${ }^{76-78}$

\section{Aspiration or Ingestion}

Aspiration or ingestion of endodontic instruments is a critical situation that can be avoided using proper precautionary measures. The rubber dam is considered the standard of care to avoid such complications and subsequent lawsuits. ${ }^{14}$ Alternatively, using throat packs should be considered for patients who are not able to tolerate rubber dams. ${ }^{79}$ The main signs included disappearance of an instrument and coughing or gagging by the patient. The situation must be further investigated immediately using radiographic imaging. These patients must be referred immediately for medical services in relation to definitive diagnosis and respective treatment. Failure to do so may result in serious consequences and death. ${ }^{79}$ It has been reported that $87 \%$ of lost instruments are swallowed and the remaining $13 \%$ are aspirated. ${ }^{80}$ In case of all aspirated and majority of ingested instruments, hospitalization and surgical intervention is usually required to remove the lost instruments. ${ }^{81,82}$

\section{Postoperative Pain}

Postoperative pain following endodontic treatment is a common symptom reported by patients. According to a meta-analysis, postoperative pain has been estimated in $5.4 \%$ patients, ${ }^{83}$ while according to prospective observations, approximately $10.0 \%$ patients reported pain 6 months following treatment. ${ }^{84}$ In terms of diagnosis, the associated pain can be broadly classified as either odontogenic pain (such as fractured teeth, missed/untreated root canals, and residual infection) ${ }^{85}$ or nonodontogenic pain (such as headache, and neurovascular and referred cardiogenic pain).$^{86}$ Additional painful conditions of nonodontogenic origin include referred myofascial and cervicogenic pain. ${ }^{87}$ After a follow-up of six months or more, the majority of patients (56\%) reported nonodontogenic pain, ${ }^{88}$ suggesting that the nonodontogenic etiologic factor must be considered during follow-up.

\section{Avoiding Malpractice Injuries during Endodontic Therapy}

The most important consideration involves adhering to the standard guideline and protocol while conducting the endodontic treatment. The strict adherence to the treatment protocols is associated with compromising the quality of treatment outcome which may lead to a malpractice claims. ${ }^{15}$ The vast majority of injuries resulting from malpractice of endodontic treatment were deemed avoidable. The up-to-date knowledge of the subject and skills competency are also one of the most crucial factors in preventing endodontic malpractice by enabling the practitioners to diagnose, plan treatment, and perform endodontic procedure with the desired prognoses. Therefore, the technical skills of the endodontists and dental practitioners performing endodontics must be improved ${ }^{15}$ with supervised working experience, workshops, and continuing professional development activities. To reduce the likelihood of legal complaints, the endodontic treatment plan, prognosis, and all possible complications should be discussed with the patient followed by signing a written informed consent. ${ }^{15}$ Additionally, the American Association of Endodontists has provided an assessment form to evaluate the case difficulty which is a valuable tool for predicting the potential complications and mishaps. ${ }^{89}$ It is highly recommended to use rubber dam isolation to minimize the risk of crossinfection and prevent accidental inhalation or ingestion of endodontic instruments of dental materials. ${ }^{90}$ Anatomical variation in the roots and root canal morphology are common. Therefore, preoperative radiographs are essential and assist operators in correctly diagnosing the extent of access cavity and negotiation of the root canals. In addition, radiographs aid in reducing the chances of procedural errors such as perforation, stripping, or ledge formation. If available, the operator must consider using advanced equipment (such as well-controlled rotary systems and cone beam computed tomography), as using such advanced technologies has been reported to reduce the risk of procedural errors and malpractice incidences. ${ }^{91}$

\section{Medicolegal Aspects}

In a fault-based liability regime, such as in the United States (in which medical malpractice cases are under the authority of each state and not the federal law), ${ }^{1,92}$ United Kingdom ${ }^{1,93}$ Canada, and Germany (in some of the cases), ${ }^{94}$ the plaintiff will have to prove liability and damages, specifically duty, breach, causation, and damages. ${ }^{1,92}$ In different countries, there may be different variations of these components but, in essence, most of them will require proof of negligence, damage, and causal connection between the act of negligence and the damage caused. ${ }^{95}$ There are some countries, such as Sweden and New Zealand, in which there is a no-fault-based liability regime, and some other countries, such as France and Germany, in which in some circumstances of medical malpractice, the regime follows no-fault-based liability. In a no-fault-based liability regime, to compensate the injured individual, the 
question of whether the healthcare provider was negligent or not is almost irrelevant. The focus usually will be on the causation and damages factors-the proof that the claimed injury was caused by the specific claimed medical treatment, and not from other reasons, and the proof of damages. ${ }^{95}$

\section{Conclusions and Recommendations}

In the recent years, a sharp rise in the endodontic malpractice cases has been observed worldwide. The current article reported various aspects of endodontic malpractice and associated factors. To avoid the incidences of endodontic malpractice and minimize the risks of procedural errors, the operator must consider ethical principles of clinical practice and adhere strictly to the standards of healthcare while performing the diagnosis and treatment. Sound theoretical knowledge about variations in the tooth internal anatomy and associated factors leading to malpractice are valuable. Therefore, operators must consider continuing professional development, including hands-on workshops, seminars, refreshers courses, and training for using various endodontic devices. In the 21st century, while the technology is changing rapidly, there is an increasing need to keep the professional up to date with regard to recent developments and provide training using the available equipment. In case of challenging situations, where the risks of procedural errors are high, a referral toward a specialist or consultant endodontist is always an appreciable option and should be considered in the best interests of the patient. In addition, the cases of failure and malpractice incidents must be registered in the local or institutional register, and should be used for discussion, feedback, and further training. Such measures can be helpful for not only keeping a record of endodontic malpractice cases but also helping in sharply reducing the number of such incidences.

\section{Conflict of Interest}

None declared.

\section{References}

1 Bal BS. An introduction to medical malpractice in the United States. Clin Orthop Relat Res 2009;467(2):339-347

2 Manca R, Bruti V, Napoletano S, Marinelli E. A 15 years survey for dental malpractice claims in Rome, Italy. J Forensic Leg Med 2018;58:74-77

3 Conrad DA, Whitney C, Milgrom P, et al. Malpractice premiums in 1992: results of a national survey of dentists. J Am Dent Assoc 1995;126(7):1045-1056

4 Ventä I, Lindqvist C, Ylipaavalniemi P. Malpractice claims for permanent nerve injuries related to third molar removals. Acta Odontol Scand 1998;56(4):193-196

5 Ozdemir MH, Saracoglu A, Ozdemir AU, Ergonen AT. Dental malpractice cases in Turkey during 1991-2000. J Clin Forensic Med 2005;12(3):137-142

6 Özdemir MH, Salaçin S, Ergönen A. The patients' rights statutes and the physicians' sensitivities. Turk Klin Tip Etigi Hukuku Tarihi 2000;8(1):32-37

7 Webber J. Risk management in clinical practice. part 4. endodontics. Br Dent J 2010;209(4):161-170
8 Selbst AG. Understanding informed consent and its relationship to the incidence of adverse treatment events in conventional endodontic therapy. J Endod 1990;16(8):387-390

9 René N, Owall B. Dental malpractice in Sweden. J Law Ethics Dent 1991;4:16-31

10 Hapcook CP Sr. Dental malpractice claims: percentages and procedures. J Am Dent Assoc 2006;137(10):1444-1445

11 Pinchi V, Pradella F, Gasparetto L, Norelli GA. Trends in endodontic claims in Italy. Int Dent J 2013;63(1):43-48

12 Brown E, Dental Services: Use, Expenses, And Sources of Payment, 1996-2000. Rockville, MD: Agency for Healthcare Research and Quality, Public Health Service, US Department of Health and Human Services; 2004

13 Swanljung O, Vehkalahti MM. Root canal irrigants and medicaments in endodontic malpractice cases: a nationwide longitudinal observation. J Endod 2018;44(4):559-564

14 Cohen S, Schwartz S. Endodontic complications and the law. J Endod 1987;13(4):191-197

15 Givol N, Rosen E, Taicher S, Tsesis I. Risk management in endodontics. J Endod 2010;36(6):982-984

16 Bjørndal L, Reit C. Endodontic malpractice claims in Denmark 1995-2004. Int Endod J 2008;41(12):1059-1065

17 Seidberg BH, Ethics, morals, the law and en dodont ics. In: Ingle JI, Bakland LK, Baumgartner JC, eds. Ingle's Endodontics. USA: PMPH; 2008 86-114

18 Zanin AA, Herrera LM, Melani RF. Civil liability: characterization of the demand for lawsuits against dentists. Braz Oral Res 2016;30(1):1-8

19 American Association of Endodontists. The standard of practice in contemporary endodontics. Endodontics: Colleagues for Excellence. Fall 2014:2-11

20 Kersten DD, Mines P, Sweet M. Use of the microscope in endodontics: results of a questionnaire. J Endod 2008;34(7):804-807

21 Creasy JE, Mines P, Sweet M. Surgical trends among endodontists: the results of a web-based survey. J Endod 2009;35(1):30-34

22 Parirokh M, Torabinejad M. Mineral trioxide aggregate: a comprehensive literature review-Part I: chemical, physical, and antibacterial properties. J Endod 2010;36(1):16-27

23 Arkes HR, Schipani CA. Medical Malpractice v. the Business Judgement Rule: Differences in Hindsight Bias. OregonLaw Rev 1994;73:587-638

24 Vehkalahti MM, Swanljung O. Operator-related aspects in endodontic malpractice claims in Finland. Acta Odontol Scand 2017;75(3):155-160

25 Daokar S, Kalekar A. Endodontic failures-a review. IOSR Journal of Dental and Medical Sciences (IOSR-JDMS) 2013;4(5):5-10

26 Barnes JJ, Patel S. Contemporary endodontics - part 1. Br Dent J 2011;211(10):463-468

27 Ahmad IA. Rubber dam usage for endodontic treatment: a review. Int Endod J 2009;42(11):963-972

28 Huggins DR. The rubber dam-an insurance policy against litigation. J Indiana Dent Assoc 1986;65(3):23-24

29 Taintor JF, Biesterfeld RC. A swallowed endodontic file: case report. J Endod 1978;4(8):254-255

30 Forrest WR, Perez RS. AIDS and hepatitis prevention: the role of the rubber dam. Oper Dent 1986;11(4):159-159

31 Wong RC. The rubber dam as a means of infection control in an era of AIDS and hepatitis. J Indiana Dent Assoc 1988;67(1):41-43

32 Miller RL, Micik RE. Air pollution and its control in the dental office. Dent Clin North Am 1978;22(3):453-476

33 Madarati A, Abid S, Tamimi F, et al. Dental-dam for infection control and patient safety during clinical endodontic treatment: preferences of dental patients. Int J Environ Res Public Health 2018;15(9):2012 
34 Anabtawi MF, Gilbert GH, Bauer MR, et al; National Dental Practice-Based Research Network Collaborative Group. Rubber dam use during root canal treatment: findings from The Dental Practice-Based Research Network. J Am Dent Assoc 2013;144(2):179-186

35 Kvinnsland I, Oswald RJ, Halse A, Grønningsaeter AG. A clinical and roentgenological study of 55 cases of root perforation. Int Endod J 1989;22(2):75-84

36 Nicholls E. Treatment of traumatic perforations of the pulp cavity. Oral Surg Oral Med Oral Pathol 1962;15(5):603-612

37 Syed A, Fahad S, Abu Bakar S, et al. Frequency of Procedural Errors during Root Canal Treatment Performed by Interns. $\mathrm{Br}$ Biotechnol J 2016;12(1):1-8

38 Abou-Rass M, Frank AL, Glick DH. The anticurvature filing method to prepare the curved root canal. J Am Dent Assoc 1980;101(5):792-794

39 Eleftheriadis GI, Lambrianidis TP. Technical quality of root canal treatment and detection of iatrogenic errors in an undergraduate dental clinic. Int Endod J 2005;38(10):725-734

40 Ingle JI. A standardized endodontic technique utilizing newly designed instruments and filling materials. Oral Surg Oral Med Oral Pathol 1961;14(1):83-91

41 Deutsch AS, Musikant BL. Morphological measurements of anatomic landmarks in human maxillary and mandibular molar pulp chambers. J Endod 2004;30(6):388-390

42 Alrahabi M, Sohail Zafar M. Evaluation of root canal morphology of maxillary molars using cone beam computed tomography. Pak J Med Sci 2015;31(2):426-430

43 Zafar MS, Alrahabi M. Cone beam computed tomography for exploring morphology of Mandibular first molar. Br J Med Med Res 2015;6(5):514-521

44 Moreinis SA. Avoiding perforation during endodontic access. J Am Dent Assoc 1979;98(5):707-712

45 Jafarzadeh $\mathrm{H}$, Abbott PV. Ledge formation: review of a great challenge in endodontics. J Endod 2007;33(10):1155-1162

46 Nagy $C D$, Bartha K, Bernáth $M$, Verdes E, Szabó J. The effect of root canal morphology on canal shape following instrumentation using different techniques. Int Endod J 1997;30(2):133-140

47 Kapalas A, Lambrianidis T. Factors associated with root canal ledging during instrumentation. Endod Dent Traumatol 2000;16(5):229-231

48 Harty FJ, Parkins BJ, Wengraf AM. Success rate in root canal therapy. A retrospective study of conventional cases. Br Dent J 1970;128(2):65-70

49 Alrahabi M, Zafar MS. Assessment of apical transportation caused by nickel-titanium rotary systems with full rotation and reciprocating movements using extracted teeth and resin blocks with simulated root canals: A comparative study. Niger J Clin Pract 2018;21(6):772-777

50 Junaid A, Freire LG, da Silveira Bueno CE, Mello I, Cunha RS. Influence of single-file endodontics on apical transportation in curved root canals: an ex vivo micro-computed tomographic study. J Endod 2014;40(5):717-720

51 López FU, Travessas JAC, Fachin E, Fontanella V, Grecca F. Apical transportation: two assessment methods. Aust Endod J 2009;35(2):85-88

52 Stewart JT, Lafkowitz S, Appelbaum K, Hartwell G. Distortion and breakage of Liberator, EndoSequence, and ProFile systems in severely curved roots of molars.J Endod 2010;36(4):729-731

53 Crane AB. A Practicable Root-Canal Technic. Philadelphia and New York: Lea \& Febiger; 1920

54 Rizvi A, Zafar MS, Farid WM, Gazal G. Assessment of antimicrobial efficacy of MTAD, sodium hypochlorite, EDTA and chlorhexidine for endodontic applications: an in vitro study. Middle East J Sci Res 2014;21(2):353-357
55 Khurshid Z, Zafar M, Qasim S, Shahab S, Naseem M, AbuReqaiba A. Advances in Nanotechnology for Restorative Dentistry. Materials (Basel) 2015;8(2):717-731

56 Johal S, Baumgartner JC, Marshall JG. Comparison of the antimicrobial efficacy of $1.3 \% \mathrm{NaOCl} /$ BioPure MTAD to $5.25 \% \mathrm{NaOCl} / 15 \%$ EDTA for root canal irrigation. J Endod 2007;33(1):48-51

57 Goldman LB, Goldman M, Kronman JH, Lin PS. The efficacy of several irrigating solutions for endodontics: a scanning electron microscopic study. Oral Surg Oral Med Oral Pathol 1981;52(2):197-204

58 Madarati AA, Zafar MS, Sammani AMN, Mandorah AO, BaniYounes HA. Preference and usage of intracanal medications during endodontic treatment. Saudi Med J2017;38(7):755-763

59 Spencer HR, Ike V, Brennan PA. Review: the use of sodium hypochlorite in endodontics-potential complications and their management. Br Dent J 2007;202(9):555-559

60 Hülsmann M, Rödig T, Nordmeyer S. Complications during root canal irrigation. Endod Topics 2007;16(1):27-63

61 Sharma S, Hackett R, Webb R, Macpherson D, Wilson A. Severe tissue necrosis following intra-arterial injection of endodontic calcium hydroxide: a case series. Oral Surg Oral Med Oral Pathol Oral Radiol Endod 2008;105(5):666-669

62 Kishor N. Oral tissue complications during endodontic irrigation: literature review. N Y State Dent J 2013;79(3):37-42

63 Zhu WC, Gyamfi J, Niu LN, et al. Anatomy of sodium hypochlorite accidents involving facial ecchymosis - a review. J Dent 2013;41(11):935-948

64 Hatton J, Walsh S, Wilson A. Management of the sodium hypochlorite accident: a rare but significant complication of root canal treatment. BMJ Case Rep 2015;2015:bcr2014207480

65 Başer Can ED, Karapınar Kazandağ M, Kaptan RF. Inadvertent apical extrusion of sodium hypochlorite with evaluation by dental volumetric tomography. Case Rep Dent 2015;2015(247547):247547

66 Becker GL, Cohen S, Borer R. The sequelae of accidentally injecting sodium hypochlorite beyond the root apex. Report of a case. Oral Surg Oral Med Oral Pathol 1974;38(4):633-638

67 Bowden JR, Ethunandan M, Brennan PA. Life-threatening airway obstruction secondary to hypochlorite extrusion during root canal treatment. Oral Surg Oral Med Oral Pathol Oral Radiol Endod 2006;101(3):402-404

68 Kavanagh CP, Taylor J. Inadvertent injection of sodium hypochlorite into the maxillary sinus. Br Dent J 1998;185(7):336-337

69 Bradford CE, Eleazer PD, Downs KE, Scheetz JP. Apical pressures developed by needles for canal irrigation. J Endod 2002;28(4):333-335

70 Kahn FH, Rosenberg PA, Gliksberg J. An in vitro evaluation of the irrigating characteristics of ultrasonic and subsonic handpieces and irrigating needles and probes. J Endod 1995;21(5):277-280

71 Strindberg LZ, The Dependence Of The Results Of Pulp Therapy On Certain Factors: An Analytic Study Based On Radiographic And Clinical Follow-Up Examinations. Mau rit zon; 1956

72 Iqbal MK, Kohli MR, Kim JS. A retrospective clinical study of incidence of root canal instrument separation in an endodontics graduate program: a PennEndo database study. J Endod 2006;32(11):1048-1052

73 Spili P, Parashos P, Messer HH. The impact of instrument fracture on outcome of endodontic treatment. J Endod 2005;31(12):845-850

74 Parashos P, Messer HH. Rotary NiTi instrument fracture and its consequences. J Endod 2006;32(11):1031-1043

75 Arens FC, Hoen MM, Steiman HR. Dietz GC Jr. Evaluation of single-use rotary nickel-titanium instruments. J Endod 2003;29(10):664-666 
76 Eikenberg SL. Comparison of the cutting efficiencies of electric motor and air turbine dental handpieces. Gen Dent 2001;49(2):199-204

77 Feil PH. A theory of motor performance and its applications to preclinical dental skill acquisition. J Dent Educ 1989;53(4):226-232

78 Alrahabi M, Zafar MS, Ahmed N. Effects of handpiece speed on the performance of undergraduate dental students in preclinical training. Journal of Taibah University Medical Sciences 2015;10(1):50-55

79 Abusamaan M, Giannobile WV, Jhawar P, Gunaratnam NT. Swallowed and aspirated dental prostheses and instruments in clinical dental practice: a report of five cases and a proposed management algorithm. J Am Dent Assoc 2014;145(5):459-463

80 Grossman LI. Prevention in endodontic practice. J Am Dent Assoc 1971;82(2):395-396

81 Susini G, Pommel L, Camps J. Accidental ingestion and aspiration of root canal instruments and other dental foreign bodies in a French population. Int Endod J 2007;40(8):585-589

82 Mahesh R, Prasad V, Menon PA. A case of accidental aspiration of an endodontic instrument by a child treated under conscious sedation. Eur J Dent 2013;7(2):225-228

83 Nixdorf DR, Moana-Filho EJ, Law AS. McGuire LA, Hodges JS, John MT. Frequency of persistent tooth pain after root canal therapy: a systematic review and meta-analysis. J Endod 2010;36(2):224-230

84 Nixdorf DR, Law AS, Lindquist K, et al; National Dental PBRN Collaborative Group. Frequency, impact, and predictors of persistent pain after root canal treatment: a national dental PBRN study. Pain 2016;157(1):159-165
85 Wolcott J, Rossman L, Hasselgren G, Management of endodontic emergencies. In: Berman LH, Hargreaves KM, Cohen SR, eds. Cohen's Pathways of the Pulp Expert Consult-E-Book: Elsevier Health Sciences; 2011 40-48

86 Mattscheck D, Law A, Nixdorf D. Diagnosis of non-odonogentic toothache. In: Hargreaves KM, Cohen S, Berman L, eds. Cohen's Pathways of the Pulp. St Louis: Mosby; 2011:49-70

87 Khan AA, Maixner W, Lim PF. Persistent pain after endodontic therapy. J Am Dent Assoc 2014;145(3):270-272

88 Nixdorf DR, Moana-Filho EJ, Law AS. McGuire LA, Hodges JS, John MT. Frequency of nonodontogenic pain after endodontic therapy: a systematic review and meta-analysis. J Endod 2010;36(9):1494-1498

89 Haug SR, Solfjeld AF, Ranheim LE, Bårdsen A. Impact of case difficulty on endodontic mishaps in an undergraduate student clinic. J Endod 2018;44(7):1088-1095

90 Estrela C, Pécora JD, Estrela CRA, et al. Common operative procedural errors and clinical factors associated with root canal treatment. Braz Dent J 2017;28(2):179-190

91 Ciobanu IE, Rusu D, Stratul SI, Didilescu AC, Cristache CM. Root canal stripping: malpractice or common procedural accident-an ethical dilemma in endodontics. Case Rep Dent 2016;2016:4841090

92 Choctaw W, Avoiding Medical Malpractice: A Physician's Guide to the Law: Springer Science \& Business Media; 2008

93 Goldberg R. Medical malpractice and compensation in the UK. Chi-Kent L Rev 2012;87:131-161

94 Stauch MS. Medical malpractice and compensation in Germany. Chi-Kent L Rev 2011;86:1139-1168

95 Blau I, Levin L. Medical malpractice: an introduction for the dental practitioner. Quintessence Int 2017;48(10):835-840 